\title{
Saturday Family Science Links Science to Life
}

Thirty families visit the T.J.Watson Research Laboratories on three consecutive Saturday mornings for two hours to participate in the Saturday Family Science at Watson program every winter. The sessions consist of hands-on experiments designed to explore fundamental principles of chemistry and physics. Thirdthrough fifth-grade children are chosen by selected area schools to participate, along with their families. Each family member is encouraged to participate in the experiments. Teachers and administrators are also invited to attend.

The Saturday Family Science at Watson program is part of the Local Education Outreach (LEO) of IBM Research. The goals of the program are to show how science relates to the real world; to challenge children to look at the world around them and to think about how things work; to encourage parents to perform hands-on science with children at home; and, lastly, to show that learning science can be fun.

The program covers three topics: Kitchen Chemistry, States of Matter, and Sound and Light. The experiments are drawn from numerous sources, and in most cases can be performed with everyday materials. Using such materials helps students relate science to their world, and shows parents and teachers that hands-on science can be done with readily available items. A few experiments involving special equipment or supplies are also included. These materials are loaned to employees or teachers for use in local schools throughout the remainder of the year.

Class leaders introduce each experiment by asking a series of questions to help the participants begin thinking about the topic. Then the experimenting and fun begin! Assistants in the room answer questions, encourage participants to think about their observations, and suggest repeating experiments if neces-

The Education Exchange highlights the experiences of scientists and engineers with local schools, along with helpful hints and resources. If you would like to share your own involvement in science education, contact: Finley Shapiro, Department of Electrical and Computer Engineering, Drexel University, Philadelphia, PA 19104, U.S.A. Phone (215) 895-6749; fax (215) 895-1695; email: shapiro@ece.drexel.edu.

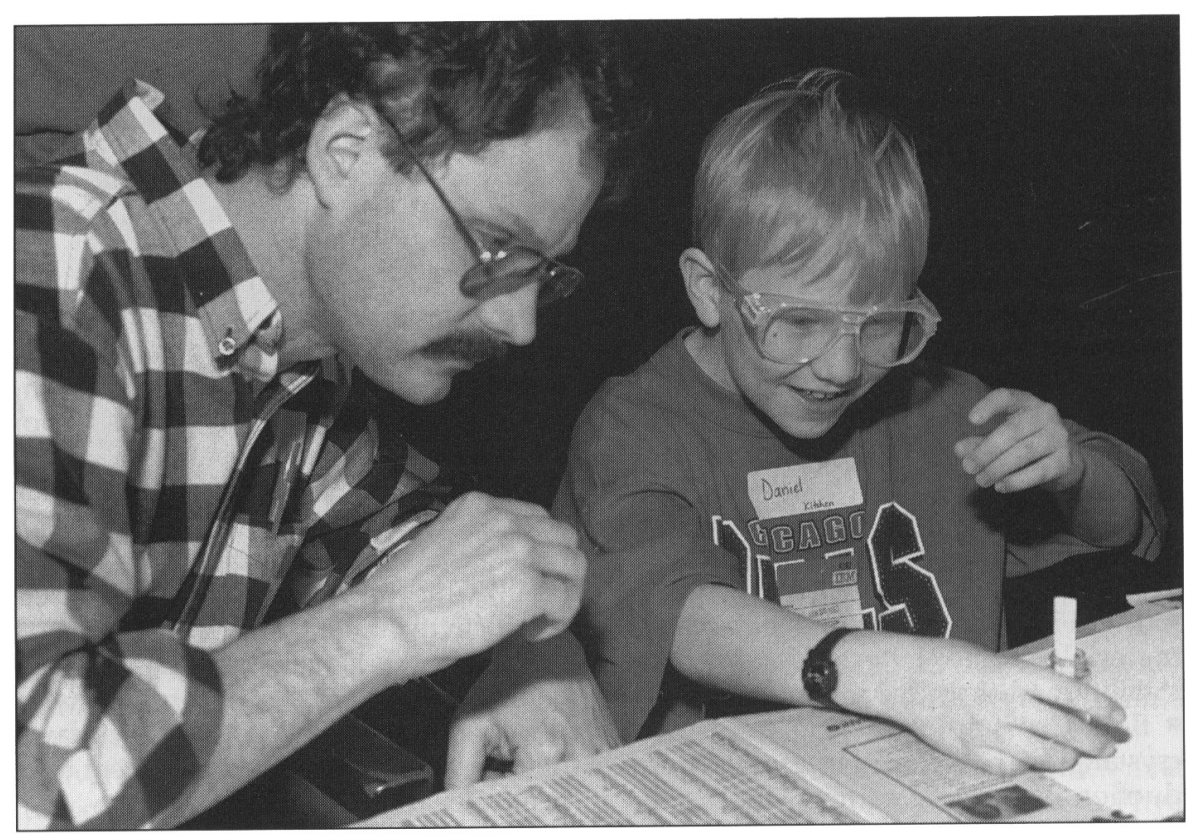

A father-son team uses paper chromatography to separate the colors in ink.

sary. They also encourage further experimentation and creativity, even if this means going off on a tangent.

Many parents are reluctant at first, but soon become active participants in the experiments. The participants' fears that an experiment may fail are soon replaced with the new knowledge that, in science, experimental failure is an important part of the learning process. Patience, creativity, and perseverance are required for successful experimentation.

The Kitchen Chemistry material is easiest to link to the real world. These experiments explore immiscible liquids and emulsions, and acid-base chemistry of everyday materials (fruits, antacids, soaps, detergents, vinegar, baking soda) using a purple cabbage indicator. The experimenters separate marker ink by paper chromatography, and make butter and cheese. They also compare the behavior of dilatant and thixotropic materials by shaking cornstarch and water, which thickens when stressed, and ketchup, which liquifies when shaken.

In States of Matter experiments, students use vinegar and baking soda, or dry ice sublimation, to blow up balloons; freeze flowers in liquid nitrogen and shatter them to show how material properties are changed by temperature; collapse a metal can by boiling water in it, sealing it and placing it in cold water; and make slime as an introduction to polymers. One popular experiment involves weighing bubble gum, and re-weighing after chewing for periods of time. For older children, the change in mass of the gum over time can be graphed. Comparisons can be made between different types (sugar, sugarless) or brands of gum.

To visualize sound, the participants make a drum from a cake pan with plastic film stretched across the face; salt spread on the film "dances" when sounds are produced. Sound sources include lids from pots, tuning forks, and paper megaphones. Wine glasses are made to sing: students add water to the glasses and predict in advance the expected note. An oscilloscope is used to display the waveforms of different sound sources, including voices, musical instruments, and tuning forks.

Color boxes are used to demonstrate light filtering. Simple fiber optic and polarized light experiments are also performed. Light bending and focusing experiments are performed using jars of water. Kaleidoscopes are made from plane mirrors as part of a series of experiments on light reflection.

High school students interested in learning to become "peer teachers" attended the Winter 1994 session. The peer teachers met with session leaders for 
an introductory discussion of the program, which also included topics such as the logistics of running the program. The teenagers then participated in the three sessions, and observed how each session leader engaged the children and their parents and siblings in the thought process as well as in doing the experiments.

High schools were paired to an elementary school in the same district. After the completion of the program, the high school students worked with the elementary school science teachers to bring hands-on experiments to elementary school classes. Pairs of peer teachers visited the classes during the school day and led the elementary students through the experiments. LEO volunteers provided support and materials to elementary school teachers and peer teachers.

Peer teaching is mutually beneficial as high school students provide a community service while learning to teach challenging material and to work with younger children. The elementary school students look up to the high school students and are enthusiastic about their visits. Pairing high school students with elementary students subtly encourages the younger children to keep studying, and encourages high school students to think about careers in education and science. Peer teaching also reaches many more elementary students than could be accommodated at Watson.

Saturday Family Science is staffed by technical and nontechnical volunteers from the research division. Although experiments were selected, tested, and documented by technical staff members, the session leaders include nontechnical staff members. One goal of LEO is to increase employee participation in local school districts. The Saturday Family Science program has helped by providing materials, handouts, and assistance to the volunteers.

Local Education Outreach at T.J. Watson includes numerous activities beyond Saturday Family Science. An Honors Math and Science program for high school juniors runs for 10 weeks during the winter. It challenges the participants in mathematical, scientific, and technological topics beyond the scope normally covered in the school curriculum. Two Students of the Month are nominated by each of eight local high schools. These students are given a tour of the laboratory, and are treated to lunch with a scientist or mathematician. IBM Research also funds a fellowship to support local science and math teachers who are interested in developing innovative teaching methods. The Education Fellow spends a year working with the Research staff toward this goal.

Catherine A. Chess

Catherine A. Chess is currently an engineer in the petroleum geology and geoscience group, and also a coordinator of the Saturday Family Science Program at the T.J. Watson Research Center of the IBM Corporation. For further information on the Saturday Family Science program or other LEO activities, e-mail her at cachess@watson. ibm.com or contact T.J. Watson Research LEO, P.O. Box 218, Yorktown Heights, NY 10598.

To receive additional information on how you can get involved in enhancing $\mathrm{K}-12$ science education, circle number 120 on the Reader Service Card.

\section{SPECIAL OFFER}

\section{Buy 2 Advertisements, Get 1 FREE!}

Purchase one ad each in the Journal of Materials Research and in the 1995 MRS Membership Directory and receive a FREE $A D$ in the MRS Bulletin.

Call Mary E. Kaufold at 412-367-3036

\section{German Furnace Technology}

25 years experience, world wide.

\section{Microwave Multilab}

furnaces are a new design for drying and sintering, fitted with two microwave chambers, can be quickly exchanged. One rectangular with inspection glass and one cylindrical for tubular high temperature furnace applications. For all laboratory, material test or special application.

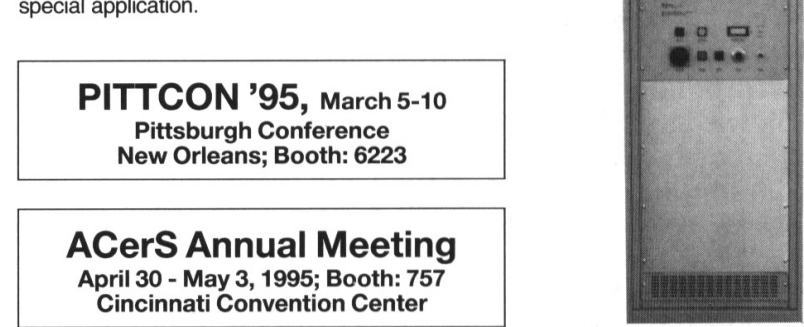

\section{Microwave Flowheater MFH}

"MFH microwave continuous flow heaters with stored program control (SPC) have been developed by Linn in close collaboeigy Their application in automatic pressure gelation (APG) plant results in very significant reductions in cycle times when producing cast-resin insulating components. A temperature gradient of $60^{\circ} \mathrm{C}$ can be maintained between the feed and delivery ends of an MFH heater when processing high-viscosity resin systems with flow rates of up to 5.0 resin systems with flow rates of up to 5.0
$\mathrm{~kg} /$ minute. Should higher temperature gradients be required, MFH heaters can either be installed in tandem or fitted with more powerful magnetrons, SPC facilitates the installation of MFH heaters in existing plant."
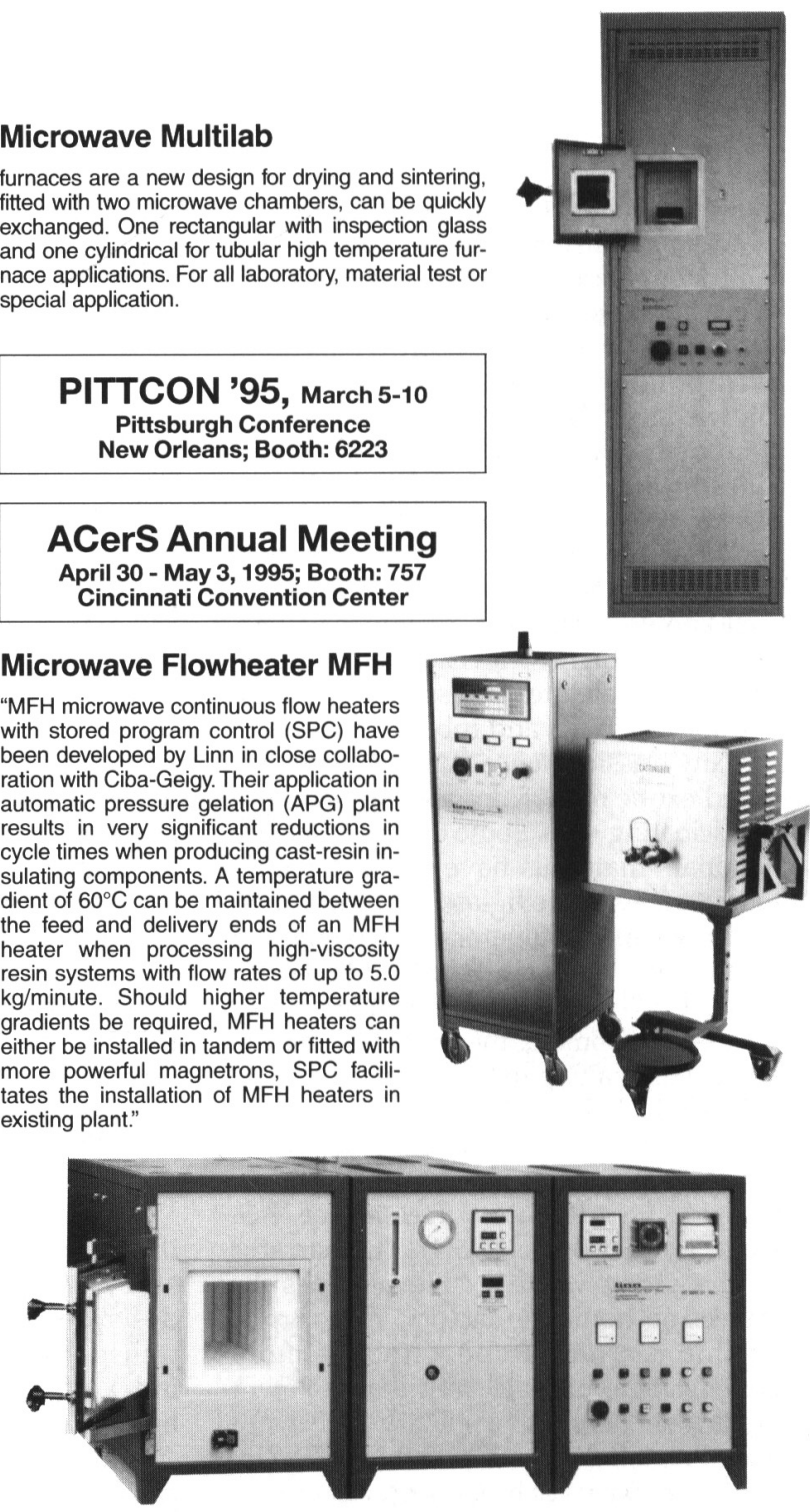

High temperature furnaces HT

for universal heat treatment and sintering under air, gas and vacuum, short heating and cooling cycles, ceramic fibre or Graphite felt insulation, $1400^{\circ} \mathrm{C}$ $-1900^{\circ} \mathrm{C}$, chamber volumes 4 to 52 liters.; special systems on request. - vacuum up to $10^{-}$

The Value Builder For Fornaces:

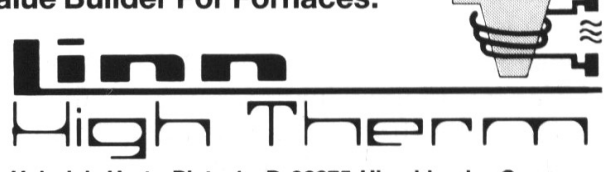

Heinrich-Hertz-Platz 1 - D-92275 Hirschbach · Germany Tel. ++49-9665-91400 • Fax ++49-9665-1720
Miero

Specialty Systems, Inc.
Phone (610) 866-8200, Fax (610) 866-7710, 10 South Commerce Way, Bethlehem, Pennsylvania 18017

Circle No. 8 on Reader Service Card. 